\title{
Um Olhar Histórico Sobre a Questão Regional e os Serviços Básicos de Saúde no Estado de São Paulo
}

\section{A Historical Overview of Regional Health Planning and Primary Care Services in the State of São Paulo}

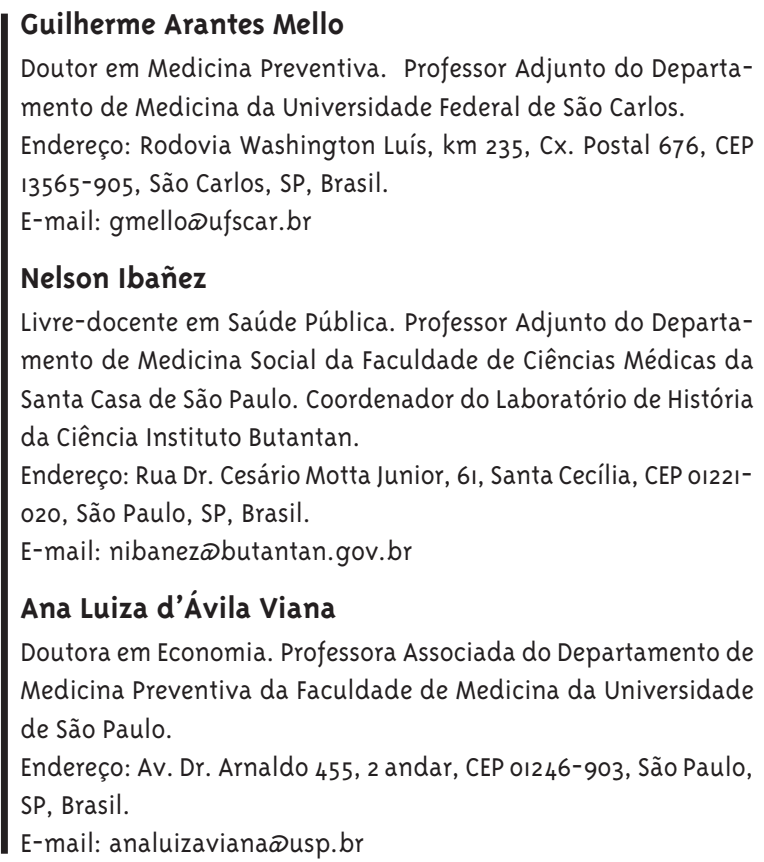

E-mail: analuizaviana®usp.br

\section{Resumo}

Com notável vigor, nos últimos anos, o debate da saúde pública brasileira tem sedimentado a ideia de que a organização regional da atenção primária à saúde é um passo inicial obrigatório para a consecução dos princípios da universalidade, equidade e integralidade do Sistema Único de Saúde (SUS). Ideário que contrapõe em definitivo o peso histórico mobilizado pela descentralização como essência do processo de organização dos serviços nos estados, mas explicita a insuficiência do modelo burocrático de gestão e dos papéis clássicos das instâncias governamentais, com reflexo particular na aptidão gerencial das Secretarias de Estado da Saúde. Sendo assim, este artigo busca contribuir com uma visão histórica geral da trajetória, as concepções, as mudanças gerenciais e o papel da instância estadual na conformação da organização regional e dos serviços básicos de saúde no estado de São Paulo. Sob o referencial da história do discurso e balizado pela introdução do modelo dos centros de saúde distritais nos anos 1920 como origem mais remota do discurso contemporâneo da atenção básica, o texto se estrutura sobre a identificação de quatro fases dinâmicas, marcadas por reformas que alteram de modo incisivo a questão regional e dos serviços básicos no estado.

Palavras-chave: Saúde pública/história; Medicina social; Atenção primária à saúde; Regionalização; Descentralização; Reforma dos serviços de saúde. 


\section{Abstract}

In recent years, public health debate in Brazil has settled the idea that regional planning of primary health care is an obligatory initial step towards the achievement of the principles of universality, equity and integrality of the Sistema Único de Saúde (SUS - National Health System). That view opposes the historical weight of decentralization as the essence of service organization in the States, but also marks the failure of the bureaucratic model of administration and of the classic roles of governmental levels, with particular consequences to the capability of the State Health Departments. Thus, this paper seeks to contribute with an overview of the ideas, management changes and the role of the State level in the conformation of the regional and primary care services organization in the state of São Paulo. Within the framework of discourse history, the text is structured on the identification of four dynamic periods, marked by health reforms that alter the regional issue and the question of primary care services organization in the State of São Paulo. The model of district health centers, introduced in the 1920 , is seen as the most remote origin of the contemporary discourse of primary health care. Keywords: Public Health /History; Social Medicine; Primary Health Care; Regional Health Planning; Decentralization; Health Care Reform.

\section{Introdução}

Sem desconsiderar a amplitude de seu contexto, nos últimos anos o debate político da saúde no país tem conferido foco privilegiado a duas grandes questões: Atenção Primária/Básica (AP) e regionalização; não sem motivo, componentes essenciais do Pacto pela Saúde (Brasil, 2006), assim como dos ideais de redes integradas que se seguiram (Brasil, 2010).

Na realidade, a relação entre AP e regionalização mostra-se de tal forma imbricada que permite inclusive assumir sua atual indissociabilidade, senão para fins didáticos. Por outro lado, a complexificação social e tecnológica cada vez mais escancara a insuficiência do modelo de administração burocrático, assim como dos preceitos clássicos da saúde pública - e medicina -, para a efetividade desta relação e do encarceramento da AP nos limites territoriais dos municípios brasileiros (premissa para o pleno funcionamento do sistema).

Esta, entretanto, não é uma discussão recente, e as propostas de alternativas e redefinições da organização sanitária no país podem se beneficiar de sua compreensão histórica. Instigado pelo desafio contemporâneo, este artigo objetiva contribuir com um enfoque histórico geral da trajetória, concepções, mudanças gerenciais e papel da instância estadual na conformação da organização regional e dos serviços básicos de saúde no estado de São Paulo. Naturalmente o texto transita com fluidez entre a influência e a indução das políticas federais, e a histórica concentração política da região metropolitana da capital.

Tendo como fio condutor a estruturação sanitária estadual e balizada historicamente pela introdução do modelo de Centros de Saúde (CSs), este artigo se desenvolve pela identificação de quatro fases dinâmicas relacionadas à atenção básica e a questão regional em São Paulo: a primeira, entre 1925 e 1967, perpassada pela alteração radical do pensamento sanitário, por várias mudanças da instância estadual e consolidação dos ideais dos CSs; a segunda, entre 1968 e 1982, em que se distingue o reforço dos princípios administrativos burocráticos, propósitos de integração e extensão dos serviços básicos de saúde, e organização regional; a terceira, entre 1983 e 2001, caracterizada pela introdução da 
visão sistêmica e integração das ações preventiva e curativas; por fim, a fase contemporânea que se estende desde 2002, marcada pelo rearranjo institucional das esferas de gestão e a complexidade das ações sistêmicas como tônica dos desafios da regionalização e atenção básica.

\section{Considerações Metodológicas}

A política de saúde como objeto faz da história do discurso - ou das ideias - um referencial bastante conveniente (Pocock, 2003). Por certo isso envolve dispor a movimentação social em segundo plano; mas o inverso é comum com a pesquisa sociológica de cunho histórico, criticada pela tendência excessiva à generalização de exemplos sociais restritos (Habermas, 2003). De fato, estudos recentes anuem sobre a influência secundária da sociedade civil organizada na conformação dos serviços de saúde (Hochman, 1998), o que favorece olhares históricos sobre ideias e instituições (Campos, 2006; Lima, 2007); cuidando sempre para que não reste a impressão de que a história se esgota nesses planos (Brandão, 2007). De qualquer forma, não deve fugir à lembrança que os discursos "vencedores" omitem os mecanismos que permitiram a legitimação da fala (Bourdieu, 2008), deixam pouco manifesto o componente popular na cultura estabelecida (Ginzburg, 2002) e facilitam a leitura acrítica do culto aos heróis.

Ao método propriamente, o que equivale dizer à compreensão histórica, importa em absoluto o contexto de enunciação, em franca discordância com a concepção de discursos e conceitos como ideias atemporais e transculturais (Jasmin, 2005). Suas implicações são claras neste estudo ocupado com a "AP” e "regionalização" em períodos em que essas expressões sabidamente não eram utilizadas.

Esse é um problema primário na história dos conceitos. Por exemplo, embora a ideia de "serviços básicos" possa ser encontrada em tempos mais remotos, a rigor dificilmente se poderia falar em "Atenção Primária à Saúde" - da qual a "Atenção Básica" brasileira é derivada - antes dos anos 1970 (Mello e col., 2009). Entretanto, é possível mapear a trajetória histórica das ideias que compõem o conceito, incluindo suas variações semânticas, sem que isso justifique a substituição extemporânea dos termos (Koselleck, 1992). Mas aqui, para além da história das ideias, importa descrevê-las em conjunto com as principais descontinuidades políticas refletidas no terreno das práticas, o que significa dizer que a distância entre a origem das ideias e sua consecução prática - geralmente longa - não será relevada.

\section{Primeira Fase: 1925-1967}

Essa fase tem seu marco inicial bem definido na Reforma do Serviço Sanitário de 1925 (São Paulo, 1925), proposta baseada no moderno referencial norte-americano dos CSs distritais trazido a São Paulo por Geraldo de Paula Souza e Francisco Borges Vieira - valores apreendidos como bolsistas da Fundação Rockefeller em Johns Hopkins (Candeias, 1984; Santos e Faria, 2002).

O novo pensamento representava uma drástica e traumática ruptura com o conhecimento da organização sanitária da escola francesa, orgulhoso de seu papel no saneamento das cidades e de toda simbologia representada pelo seu patrono Oswaldo Cruz (em São Paulo também Emílio Ribas). Basicamente esse movimento, que outros bolsistas e representantes da Fundação estenderam aos estados brasileiros mais importantes, e de resto aos quatro cantos do planeta, foi responsável por delinear toda a base do pensamento contemporâneo da organização sanitária (o que na realidade, em maior ou menor grau, dispõe as rupturas que se seguiram muito mais como atualizações e reordenamentos relacionados à complexidade social, política e tecnológica epocal).

Compunha o ideário dos CSs: dedicação médica de tempo integral, foco familiar, exame médico periódico, atenção materno-infantil, vacinação, vigilância sanitária e atendimento clínico a doenças transmissíveis, além da visitação domiciliária de rotina (sempre com visitadoras adaptadas em função da indisponibilidade de enfermeiras no país), tudo isso voltado para o verdadeiro objetivo final: a educação sanitária (Souza e Vieira, 1936). Uma característica do discurso brasileiro dos CSs, muito marcante em São Paulo, foi sua defesa incondicional como serviço exclusivamente preventivo e de educação sanitária - conceito então bastante vago -, sem a oferta de qualquer assistência clínica que 
não tivesse caráter epidemiológico (Souza, 1939). Proposição de grande resistência entre sanitaristas renomados (Barbosa, 1930).

Embora a reforma paulista de 1925 tenha tido dificuldades em sair do papel e a terminologia "Centro de Saúde" tenha mesmo sido suprimida na reforma de 1931 (São Paulo, 1930; 1931), a realidade é que seu núcleo ideológico representado pela educação sanitária e visão geral preventivista manteve-se preservado, até pela força da escala de difusão desses princípios. Certamente deve ser considerado que toda essa discussão de modelo sanitário tinha um cunho eminentemente de eficiência administrativa e de vigilância epidemiológica, isto é, sem a conotação moderna de cuidado. Mas de forma alguma resta dúvida de que esse período foi a origem da ideia da atenção básica (Campos, 2007).

Duas questões de interesse específico podem ser destacadas sobre esse início. A reforma do Serviço Sanitário paulista de 1906 (São Paulo, 19o6) já promovia a divisão político-territorial do estado em 14 distritos, reorganizados em circunscrições (Mascarenhas, 1949). Entretanto, a ideia de distrito presente no CS mantinha uma conotação administrativa que se relacionava ao planejamento da assistência descentralizada a uma população geograficamente delimitada (estimada em cerca de 150 mil pessoas) grosso modo próximo do que se entende atualmente por distrito sanitário (Barreto e Fontenelle, 1935). Por sua vez o debate da descentralização mobilizava a política brasileira desde a constituição imperial e havia pautado grande parte da retórica presente nas primeiras reformas do Serviço Sanitário paulista (Telarolli Junior, 1996). Também nesse caso, o conceito de descentralização trazido pelos CSs mostrava-se diverso, traduzindo-se na proximidade do serviço com a população servida. Mix conceitual responsável por certo confundimento histórico no debate regional.

A par dessas questões, uma terceira característica ainda pouco explorada na literatura pode ser assinalada. 0 pensamento norte-americano dos CSs representou também a introdução definitiva da racionalidade burocrática no pensamento sanitário brasileiro, com sua organização centralizada, hierarquizada e eminentemente técnica - tão afeita ao discurso de Paula Souza (e principalmente de seu pai, Francisco de Paula Souza, fundador da escola Politécnica e um dos maiores responsáveis pela introdução do pensamento racional no país). Uma cultura administrativa fortemente conflituosa com a administração carismática e patrimonialista que prevalecia naquele tempo.

João de Barros Barreto foi o grande mentor da construção de uma burocracia nacional em saúde, com forte apelo para as questões regionais e estruturação estatística. Por suas mãos, e sob a máxima da "desconcentração" preconizada por Oliveira Viana (Viana, 1999) - centralização política com descentralização administrativa -, os preceitos da organização sanitária baseada no modelo dos CSs viram-se fortalecidos nacionalmente na política de saúde varguista (Fonseca, 2007). Nesse tempo, o CS distrital retorna à política de saúde paulista através da reforma de 1938 (São Paulo, 1938), notavelmente inserido no espectro normativo da administração federal (Barreto, 1937).

Mas viria a ser o Serviço Especial de Saúde Pública (SESP), criado em 1942, que em sua autonomia político-administrativa definiria as diretrizes de uma organização regional, descentralizada, coordenada e integrada no terreno das práticas (Campos, 2006). Contribuiu para essa situação a primazia federal concedida às campanhas de erradicação de doenças infectocontagiosas que se seguiu ao governo Kubitschek, legando aos estados a organização dos serviços locais e regionais, realizados fundamentalmente com a participação do SESP (Programa, 1955; Penido, 1958). O pensamento sanitário paulista sobre a organização sanitária teve nesse serviço uma escola fundamental (Ramos, 1972).

Por volta dos anos 1950 os conceitos de CSs e regionalização já se mostravam amadurecidos no contexto internacional (Grant, 1953), acompanhados de perto pela literatura brasileira. Sendo assim, é interessante perceber a ausência da "regionalização" nos textos nacionais desse período, em nítido contraste com o fervor que cercava os CSs e a "descentralização”. É possível que a precariedade social do "imenso hospital" que se chamava sertão não permitisse estender naquele conceito. Entretanto, a ideia geral de integração de serviços e participação no desenvolvimento social, ainda que restrita, pode ser identificada no discurso da estruturação dos 
serviços locais e regionais (Barreto, 1939; Penido, 1958). É bem provável que parte da ausência literal da "regionalização" nesse período se deva ao confundimento de seu campo conceitual com a insuperável retórica da descentralização.

Ninguém melhor do que Rodolfo Mascarenhas documentou a saúde pública paulista desse período (hors-concours no quesito "referência omitida"). Seus trabalhos são enfáticos em esclarecer que o problema fundamental da saúde pública paulista relacionava-se primariamente à ingerência política e não à questão dos princípios organizativos. Pioneiro em reconhecer a prioridade da decisão política sobre a técnica - na contramão do pensamento burocrático estabelecido por Paula Souza - sua crítica direcionava-se a "politicalha", nepotismo, favorecimentos pessoais e ao "feudalismo administrativo" (Mascarenhas, 1949). Não deixou de chamar a atenção para o arcaísmo da reforma de 1938, o primeiro período de relativa estabilidade política no estado depois da revolução varguista, modificada de acordo com conveniências pessoais. Na defesa de um modelo único de unidade sanitária responsável por todas as atividades locais de saúde pública, descreve a confusa organização no interior do estado em 1953: “9o dos chamados 'centros de saúde', 271 PAMS, 173 postos de puericultura, 26 dispensários de tuberculose, 204 unidades (dispensários, postos e subpostos) de tracoma, 53 unidades de profilaxia da malária, 20 unidades de profilaxia da lepra e 665 gabinetes dentários”. Mas já não era tempo de desconhecer a necessidade de integração assistencial, e o próprio autor questiona o gasto desproporcional com os serviços de saúde pública (mais de 6o\% do orçamento) diante dos serviços hospitalares: “a medicina preventiva só é bem aceita pela população quando recebe o auxílio de uma aparelhagem básica da medicina curativa" (Mascarenhas, 1954).

O passar dos anos apenas acentuaria a distância entre o discurso e as práticas. Se a ideia de integralidade adquiria contornos cada vez mais abrangentes (Mascarenhas e Piovesan, 1961), a administração sanitária paulista estagnava-se em uma cultura clientelística e baixa capacidade de planejamento. Mais de duas décadas depois da reinserção dos CSs na política estadual, Mascarenhas (1964) manifestava desalento com a excessiva desordem e descontinui- dade da organização sanitária do estado, concluindo pela necessidade de uma ampla reforma: "que não seria propriamente uma reorganização e sim uma organização, pois esta secretaria de Estado jamais foi organizada”.

\section{Segunda Fase: 1968-1982}

Uma ampla reforma na Secretaria do Estado da Saúde de São Paulo (SES-SP) seria promovida apenas na gestão de Walter Leser no final da década de 1960; marco do segundo período da organização sanitária paulista aqui considerado (São Paulo, 1968).

Embora suficientemente vigorosa para se situar como divisor de águas, não pode ser comparada à violência da ruptura política e epistemológica definida pela reforma de 1925. Pelo contrário, Leser, que teve Paula Souza como mentor de seu doutorado, aproveita a singularidade do momento justamente para a tão esperada oportunidade de redefinir uma estrutura burocrática altamente técnica na Secretaria de Saúde, e finalmente conformar os CSs como unidades sanitárias polivalentes: "o verdadeiro eixo da organização, responsável pelos problemas de saúde da comunidade" (Leser, 1972, apud Sauveur, 1983b).

Uma grande reforma política na saúde marcou o contexto federal daquele momento: a unificação dos Institutos de Aposentadorias e Pensões (IAPs) no Instituto Nacional de Previdência Social (INPS). Nesse clima de reordenamento na saúde, vários fatores concorreram para viabilizar uma reforma estrutural completa na SES-SP. Desde a reforma de 1938, a Secretaria de Saúde tropegava sobre indefinições reformistas: "há 21 anos a Secretaria aguarda a reorganização, embora oito projetos tenham sido elaborados sem sucesso" (Leser, 1968). Por outro lado, avolumavam-se os ideais da medicina comunitária e a medicina preventiva decretava as práticas como seu espaço natural, inquietação que nos anos seguintes desembocaria em várias experiências-piloto de reorganização das práticas, tendo no Projeto Montes Claros o mais audacioso deles (Fleury, 1995). Mas a questão decisiva, não resta dúvida, diz respeito à reforma da administração pública federal referendada pelo Decreto Lei 200o, de 25 de fevereiro de 1967 - fruto do esgotamento da 
capacidade decisória populista -, e sua congênere estadual representada no Decreto 48.040, de o1 de agosto de 1967 (Sauveur, 1983b).

Não poderia ser outro o principal fundamento envolvido: a "integração". Naquele momento um conceito bastante próximo do que se estenderia ao SUS na forma de "integralidade":

A medicina e a Saúde Pública devem ser aplicadas de modo global, integral, sem divisão rígida entre atividades preventivas e curativas. 0 indivíduo, doente ou sadio, não pode ser observado com exclusão de seu meio físico, biológico e social. Os problemas de saúde pública devem ser estudados de modo integral, em contato com outros problemas não sanitários [...]. Surge o direito à saúde, extensivo a todos os cidadãos ${ }^{1}$.

A reforma define as atribuições dos órgãos normativos da saúde; estudar, planejar, orientar, coordenar, supervisionar e executar ações que visem melhorar as condições de saúde promovendo a saúde, prevenindo doenças e participando das medidas de recuperação da saúde; de pesquisas voltadas para os problemas da saúde e de articulação com outras entidades para esse fim. Nesse propósito, a reforma buscou a descentralização técnico-administrativa através da criação de dez Divisões Regionais - com 67 Distritos Sanitários - e uma estrutura de quatro Coordenadorias: Saúde da Comunidade; Assistência Hospitalar; Saúde Mental e Serviços Técnicos Especializados - estrutura que perdurou até 1985. Destacava-se em importância e tamanho a Coordenadoria de Saúde da Comunidade, responsável por garantir uma rede de unidades locais escalonadas segundo a complexidade exigida (Rodolfo Mascarenhas foi designado para sua direção, mas foi impedido por questões de saúde).

A reforma pode ser resumida nas seguintes propostas: integração local dos serviços, descentralização executiva com centralização normativa, e implementação de sistemas permanentes de planejamento, estatística e treinamento (Mascarenhas, 1973; Sauveur, 1983b; Viana, 1994). Na ausência de quadros especializados a Faculdade de Saúde Pública da Universidade de São Paulo (USP) foi instada à formação em massa de novos sanitaristas (Souza e col., 1975).

Do ponto de vista da gestão regional, podem ser apontados alguns de seus traços marcantes: a provisão assistencial básica por meio de rede própria de serviços, hierarquizada em cinco níveis de complexidade e abarcando a gerência de programas e atividades relacionadas à vigilância epidemiológica e sanitária; o surgimento do distrito sanitário como estrutura intermediária de coordenação para as regionais de saúde; a coordenação de atividades com os municípios, restrita a alguns convênios e cessão de terrenos para a construção de unidades.

Aos limites deste texto interessa ressaltar três considerações permitidas neste ponto: 1) em que pese a mobilização em torno da reforma administrativa ter concorrido para atualizar o debate à complexidade epocal, os princípios norteadores da reforma de 1968 assentam-se eminentemente sobre a mentalidade clássica dos CSs fundamentada nas décadas anteriores; e que se veem refletidas na estrutura do decreto, atividades elencadas, defesa dualista, criação da carreira sanitária, fortalecimento burocrático, entre outras. Seus ideais de "saúde da comunidade" bebem diretamente na fonte dos seminários patrocinados pela OPAS em Viña Del Mar (1955) e Tehuacán (1956) - em que Leser teve participação destacada no primeiro e Mascarenhas foi o grande difusor acadêmico (Mascarenhas e col., 1961, 1962). Portanto, e não deve ser visto como demérito, a reforma de 1968 pertence muito mais à primeira metade do século do que à segunda; 2) independentemente disso, e embora não mencione a expressão, não seria exagerado considerar essa reforma como genuíno contexto em que se despertou o moderno debate da Atenção Primária/Básica em São Paulo (Sauveur, 1983a) típico dos anos 1970, ainda que seus referenciais específicos não o tenham alcançado (Pareta e col., 1976); 3) foi, por fim, um momento de potente reafirmação de uma cultura institucional que viu nos princípios da racionalidade burocrática e descentralização a garantia da eficiência e eficácia das atividades.

Em síntese, mais do que uma ruptura essencial

1 MASCARENHAS, R. S. Introdução a administração sanitária. São Paulo: Faculdade de Saúde Pública da Universidade de São Paulo, 1972. [Disciplina de Administração Sanitária]. (mimeo). 
na organização dos serviços de saúde, a reforma de 1968 representou a reafirmação de uma cultura institucional de base, inserida no tríplice objetivo da reforma da administração pública mais ampla: "eficiência operacional, eficiência administrativa e valorização do servidor público, visando obter maior eficácia na ação governamental" (Sauveur, 1983b). E não era pouco. Yunes e Bromberg (1971) descrevem bem o problema gerado pela ausência histórica de critérios racionais de instalação dos equipamentos metropolitanos da saúde e a acentuada insuficiência profissional: "falta de coordenação entre os poderes públicos responsáveis pelas unidades sanitárias, levando a supercobertura de algumas áreas e o total abandono de outras".

Apesar de todas as restrições políticas, aquele era um momento de ebulição social pelo direito do usufruto do desenvolvimento e, em um campo historicamente problemático, a reforma falhava em aumentar efetivamente o acesso público à assistência curativa, preservando a dicotomia da atenção preventiva na saúde pública e curativa no âmbito previdenciário. Na prática, a reforma se viu obstada inclusive pelo descontrole da própria burocracia vista como redentora: "os nomes foram mudados, as condições físicas, humanas e materiais praticamente permanecem" (Yunes e Bromberg, 1971; Sauveur, 1983b).

Somente na segunda metade da década de 1970 se veria a ampliação da assistência médica individual nos CSs paulistas com a implantação do modelo de "Programação em Saúde”, justamente na segunda gestão de Leser. Difundida inicialmente pela OPAS, a ideia do "modelo programático" havia balizado a V Conferência Nacional de Saúde, tendo sido reforçado pela criação da Secretaria Nacional de Ações Básicas de Saúde (SNABS) em 1976 (Yunes, 1975; Tanaka e col., 1992). Não deixava de representar um escalonamento da tensão social por acesso clínico universal na saúde pública, questão de longa data que se agudiza no período e se vê identificada nos ideais do II Plano Decenal de Saúde para as Américas (1971-1980); II Plano Nacional de Desenvolvimento (PND); Plano e Extensão de Cobertura (PEC).

Assim, embora o elenco de atividades clínicas e o arcabouço da "programação" configurem-se como uma clara transição política, não teve força de ruptu- ra essencial no contexto da atenção básica (embora considerá-lo não seja exatamente inapropriado); mas uma espécie de continuum da reforma de 1968, representada no próprio Leser. A incorporação clínica nos CSs não era uma excepcionalidade em si, haja vista ter sido introduzida décadas antes pelo SESP (Penido, 1958).

$\mathrm{Na}$ "programação" as atividades foram tipificadas em "rotina" e "eventual", e a assistência médicosanitária dividida entre "Assistência à Saúde da Criança" (pediatria, puericultura e adolescente) e "Assistência ao Adulto" (gestante, tisiopneumologia, dermatologia sanitária, saúde mental e doenças crônico-degenerativas). Superava-se enfim no terreno das práticas a defesa majoritária dos CSs exclusivamente para ações preventivas, dualismo superado no discurso acadêmico desde os anos 1950. Contudo, ao se regular pela epidemiologia e vigilância, o acesso clínico da programação ficou inicialmente bastante contaminado. Somente na década seguinte, dentro de uma nova geração de pensamento sanitário de esquerda, a discussão ganharia contornos mais elaborados e um corpo de argumentação consistente (Nemes, 1990), muito embora também com limites aparentes (Ayres, 1995).

De qualquer forma, mantinha-se o grave problema da falta de integração no sistema, decorrência tanto da autonomia dos subsistemas quanto do fato de que os serviços básicos se orientavam pela regionalização e o nível hospitalar se organizava por especialidades (Viana, 1994). Extinta em 1982, a programação deixou um passado de resistência na região metropolitana de São Paulo, que mostrou ainda certa inversão de prioridades das consultas eventuais em relação às programáticas (Nemes, 1990).

O tempo se encarregaria de mostrar que não se foge facilmente de uma cultura institucional tão arraigada (cujas raízes liberais alcançam o pensamento roquefeleriano dos anos 1920). O que o eminente sanitarista Plácido Barbosa (1930) se queixava sobre os CSs na transição para os anos 1930: "Que espécie de obra de saúde pública iríamos fazer desamparando, na doença, os que necessitam de amparo e assistência?"; Barros Barreto, dualista convicto, não tinha como negar na década seguinte: "dificilmente se inculcará como mais benéfico à mentalidade de 
uma mãe, que vê seu filho doente preterido por uma criança sã" (Barreto, 1939); Henrique (Penido, 1958) reafirmava trinta anos depois, sobre a insatisfação da população, que ia ao CS receber "conselhos e vacinas em vez de tratamento para suas enfermidades"; por fim Adib Jatene (à frente da SES-SP) insistia nos anos 1980 na $7^{\text {a }}$ Conferência Nacional de Saúde: "Não querem centros de saúde para vacinar e fazer as ações preventivas. Exigem a presença constante do médico" (Jatene, 1980).

\section{Terceira Fase: 1983-200I}

As políticas de saúde da década de 1980 estiveram contextualizadas pela crise do modelo previdenciário e, portanto, das iniciativas federais e estaduais de rearranjo do setor público que visavam novas formas de relação tanto no financiamento e convênios quanto na direção colegiada dessas esferas. Passagem bastante conhecida, as tentativas frustradas de programas como o Prevsaúde desembocam nas Ações Integradas de Saúde (AIS) e no Sistema Unificado e Descentralizado de Saúde (SUDS), embriões da proposta de construção do SUS no país.

Em termos práticos, os estados deixam a posição de receptores das políticas federais para se tornarem interlocutores do processo. A definição de atribuições do estado passou então a envolver planejamento, coordenação e direção das atividades de prestação de serviços de assistência à saúde no âmbito de determinada área geográfica. A reestruturação do modelo instituído na SES-SP pela reforma de 1968 foi um dos desdobramentos das AIS no estado (Tanaka e col., 1992). Em 1986, são criadas a Comissão Regional Interinstitucional de Saúde (CRIS), órgão colegiado de planejamento e gestão; e os Escritório Regionais de Saúde (ERSAs), unidades de gerência descentralizadas (São Paulo, 1986a) ${ }^{2}$. Notem-se no decreto os objetivos gerais da reforma: “[...] integração, hierarquização e regionalização dos serviços de saúde [...]”; sem qualquer referência direta à "descentralização".

Aponta-se para uma articulação mais sistêmica entre a rede serviços de atenção básica, hospitalar e das ações tradicionais da saúde pública em geral. Tem-se assim do ponto de vista regional: a descentralização radical da estrutura da SES-SP (nível de departamento), que se incumbem da gerência da provisão de serviços - não somente por meio os CSs, mas de todas as unidades da SES da área de abrangência -; a direção colegiada regional envolvendo outras esferas de governo e prestadores na assistência médica hospitalar; a criação de instâncias reguladoras regionais de avaliação; o controle de prestadores de serviço; o processo de transferência da rede básica estadual para os municípios e início da incorporação dos municípios na gestão regional.

Em outras palavras, os anos 1980 redefinem o discurso sanitário que pautaria as políticas contemporâneas de saúde: integralidade; atenção básica/ primária; prioridade do setor público sobre o privado; e organização dos serviços com a ótica da descentralização, regionalização e hierarquização. Mais uma vez, não se pode assumi-la como uma ruptura epistemológica definitiva com a matriz original dos CSs, mas, para usar a imagem anterior, decididamente a década de 1980 pertence muito mais às décadas seguintes do que às predecessoras. Tanta impregnação do novo léxico da AP não mais se pôde dissociar do fortalecimento da sociedade civil organizada como demandadora das ações básicas na saúde (Gerschman, 1995); quanto da questão regional.

Resoluto em ser a exceção que confirma a regra, o estado se antecipa às próprias mudanças federais em curso e marca uma nova era na política de saúde do estado com a implementação do Programa Metropolitano de Saúde (PMS) em 1982 - escolhido como marco do período. O PMS fora o principal resultante do "Projeto de Expansão dos Serviços Básicos de Saúde da Grande São Paulo", desenvolvido a partir de 1979 como corolário da pressão exercida por movimentos populares de saúde e diagnóstico da precariedade sanitária da região metropolitana.

Dois anos depois é organizada a implantação do programa em cinco áreas priorizadas: Cotia, Mauá, Caieiras (municípios da Grande SP), Fregue-

\footnotetext{
2 Foram criados 15 ERSAs na Região Metropolitana da Grande São Paulo, diretamente subordinadas ao Coordenador do Programa Metropolitano de Saúde, e 42 nas Regiões de Governo. O Decreto n 24.923, de 17 de março de 1986, alterou a estrutura dos Departamentos Regionais de Saúde, adequando-os às Regiões de Governo criadas pelo Decreto nº 22.970, de 29 de novembro de 1984 (São Paulo, 1984 , 1986a).
} 
sia do Ó e Itaquera-Guaianazes (bairros periféricos do Município de SP). Os seguintes critérios foram observados: áreas periféricas carentes e com forte demanda popular por melhorias; locais em que a colaboração entre Estado, Município e Inamps já existisse; e áreas onde o novo modelo já estivesse em andamento, proporcionando uma implantação mais rápida e com menor investimento (caso da experiência de Cotia). Seus objetivos centrais estabeleciam conexão direta com todo o movimento da reforma sanitária que culminaria nas formulações da $8^{a}$ Conferência Nacional de Saúde: universalização da atenção; equidade no atendimento; integralidade das ações de saúde; descentralização e participação social (Ibañez e Viana, 1986).

Interagindo com as políticas federais, em particular com as Ações Integrais em Saúde (AIS), o PMS deu início efetivo ao processo de regionalização e descentralização na saúde paulista e à definitiva incorporação universal da assistência médica individual pelo setor público. Como de praxe, os objetivos iniciais foram dificultados pelos problemas já bem conhecidos: despreparo do setor público no campo da saúde, especialmente hospitalar; falta de integração; dificuldade de recursos humanos, especialmente médicos; baixa remuneração; ausência de plano de cargos e carreira; baixa interação com as escolas de medicina; baixo controle popular; dificuldade de planejamento etc. (Viana, 1994).

A transição representada pelo PMS se completaria com a implantação do Sistema Unificado e Descentralizado de Saúde (SUDS) em 1987; ao qual se seguiu a criação dos Núcleos de Atenção Integrada (NAIs). Tendo em vista a universalização da cobertura, os NAIs foram precursores em abolir a necessidade das carteiras previdenciárias do Inamps para atendimento, passando a exigir apenas um documento de identificação do usuário, além de se preocuparem com a extensão do horário de cobertura, a readequação do espaço físico, o funcionamento ininterrupto das unidades durante a jornada, entre outras características. Em 1989, conformavam $85 \%$ dos CSs estaduais na região metropolitana de São Paulo. Sem surpresa, sua atuação acabou limitada pela série de antigas dificuldades: a insolvível integração entre a atenção básica (porta de entrada) e rede hospitalar; a dificuldade de incor- poração médica nas cinco clínicas básicas e prontoatendimento (baixo envolvimento das equipes do SUDS e rotatividade médica); e carência de recursos humanos adequados ao trabalho multiprofissional (Viana, 1994).

A instituição do SUS concorreu para reforçar a continuidade das reformas que vinham ocorrendo nos estados, com destaque para a regulamentação do processo de descentralização da gestão para a esfera municipal, promovida pelas Normas Operacionais Básicas (NOBs) da década de 1990. As novas diretrizes levaram ao remodelamento da representação regional da SES-SP em 1995, com a substituição das ERSAs pelo modelo das Direções Regionais (DIRs). Expressava duas preocupações nucleares: o enxugamento da máquina administrativa com a diminuição dos 62 ERSAs para 24 DIRs; e a reorientação do papel das regionais, tendo em vista a municipalização da rede básica e a necessidade de uma coordenação mais técnica do processo de gestão estadual (estruturada em Núcleos de Planejamento, Avaliação e Desenvolvimento; Grupos de Vigilância Epidemiológica; Grupos de Vigilância Sanitária; e dos Núcleos de Apoio à Assistência). 0 nível central foi unificado em duas grandes Coordenadorias: Grande São Paulo e Interior.

Além de novos desafios, todo esse movimento testemunhou também a emergência de antigos conflitos. A instituição do Piso de Atenção Básica (PAB fixo e variável) possibilitou a retomada e o fortalecimento da política da atenção primária no nível local, mas paradoxalmente num fluxo de centralização normativa federal, principalmente representada no desenvolvimento do Programa de Agentes Comunitários de Saúde (PACs) e Programa Saúde da Família (PSF). A participação dos estados claramente se viu enfraquecida nesse processo, passando a concentrar suas ações na provisão de serviços na área hospitalar e no apoio e produção e distribuição de medicamentos. Como descreve Yunes (1999, p. 68).

[...] o processo de descentralização instaurado pelo SUS, centrado na relação União-município, deixou à margem os estados como instâncias de planejamento, financiamento, avaliação e controle. Com isso, permaneceram na disputa pelo papel de prestador, com o SUS deixando 
de dispor de uma instância articuladora e otimizadora dos recursos disponíveis em cada município, atravancando assim a possibilidade de se programar e de operar redes de serviços de âmbito regional.

Mas a estrutura administrativa proposta e a regulamentação das atribuições regionais já revelavam a tendência de repensar o papel estadual na gestão do SUS na direção do planejamento regional, apoio aos municípios e regulação do sistema.

\section{Quarta Fase: 2002-atual}

Enquanto os demais períodos foram deliberadamente assinalados por reformas estaduais, essa última fase tem na emissão da Norma Operacional da Assistência à Saúde (NOAS) 01/2001 sua referência (Brasil, 2001). Justamente por ter sido a responsável por atrelar e fornecer um contexto de maior consistência aos parâmetros de avaliação da AP, papel das esferas estaduais e a regionalização. Embora se possa ver nisso um novo "paradigma" - da regionalização assistencial -, é certo que representa muito mais um reforço e do movimento anterior do que uma ruptura essencial.

Até então, inadvertidamente, o debate sanitário alimentou de modo equivocado a relação entre descentralização e AP. Em plena era SUS a ideia de regionalização que se esforçava por um lugar ao sol desde o Prevsaúde e AIS manteve-se eclipsado pela força histórica do debate da descentralização, contribuindo não somente para a subestima da complexidade da assistência regional, mas para seu próprio óbice:

O que essas relações entre a regionalização e a municipalização mostram é, em suma, a tendência à autonomização dos municípios no que se refere à lógica do sistema único, hierarquizado, descentralizado, regionalizado e integrado. Em outras palavras, a etapa final da constituição do SUS, entendida como municipalização, pode ocasionar a negação mesma do desenho original do sistema (Viana, 1994, p. 168-169).

Excessivamente normativa, como de fato rezava a tradição, a NOAS foi com razão acoimada de "engessar" o sistema, desconsiderando a heterogeneidade regional e promovendo uma regionalização autárquica. Mas a realidade é que a NOASs (2001 e 2002) definem um novo patamar discursivo à organização sanitária brasileira, no qual as ações da AP ganham contornos mínimos aceitáveis e, de modo cabal, a descentralização desacompanhada do debate regional perde grande parte do sentido. Em poucos anos a regionalização se vê no centro do discurso da organização sanitária através do Pacto pela Saúde (Brasil, 2006) - na incansável busca do sanitarismo nacional pela normativa menos normativa.

É neste contexto que em 2006 a administração regional em São Paulo volta a ser reformulada com a transformação das DIRs em dezessete Departamentos Regionais de Saúde, em nova tentativa de arranjos institucionais apropriados à ação regional da SES: planejamento regional; coordenação e articulação dos sistemas municipais; além de apoio aos municípios na organização de sua rede básica. Entretanto, essas próprias funções passam a ser dialogadas com os Colegiados de Gestão Regional instituídos pelo Pacto, tensionando ainda mais a capacidade técnica e política dos entes.

A conjuntura metropolitana da capital representa como nenhuma outra as dificuldades, contradições e distorções experimentadas pela autonomia municipal nesse período. Em São Paulo a municipalização da rede básica chegou ao termo apenas em 2002, motivada pela opção anterior de estabelecer um sistema próprio gerido por cooperativas: o "Plano de Assistência à Saúde" - PAS; reformulado em 1999 para "Sistema Integrado Municipal de Saúde" (SIMS). Assim como seu predecessor naufragou em denúncias de corrupção, iniquidade, ausência de controle social, dificuldades de acesso e integração; operando na prática como um simples serviço de pronto-atendimento (Guedes, 2003).

A aproximação do município com o PSF se deu ainda em 1996 através de convênio entre o Ministério da Saúde, SES-SP e Hospital Santa Marcelina, que passou a gerenciar unidades básicas do estado na Zona Leste da capital, sob a denominação de "Qualis" (Qualidade Integral à Saúde). Dois anos adiante tinha início o Qualis/PSF nas Zonas Norte e Sudeste, sob gerenciamento da Fundação Zerbini, abarcando no total uma população de 400 mil pessoas (Capistrano Filho, 1999). Experimentava-se uma 
verdadeira mixórdia assistencial, com unidades básicas do PAS/SIMS em áreas de interseção com o território de unidades estaduais com PSF; enquanto o acesso a esse último poderia significar o lado da rua em que se residia. Por sua vez, as unidades estaduais podiam abrigar funcionários da administração direta e indireta - o que se gerava problema do ponto de vista da diferenciação salarial para a equipe do PSF.

Com a troca do executivo municipal em 2001, logo se anunciou a adesão do sistema municipal ao SUS, com a retomada dos processos de descentralização e regionalização, priorização da administração direta e "adoção do Programa de Saúde da Família como modalidade estruturante da assistência à saúde" (Alves Sobrinho e Capucci, 2003). As administrações posteriores mantiveram o modelo baseado no PSF, mas alinhando-o à política de fortalecimento da parceira público-privado que já vinha acorrendo no estado com a rede hospitalar (Ibañez e col., 2001).

Na cidade de São Paulo a introdução das unidades de "Assistência Médica Ambulatorial" (AMA), pronto-atendimentos elencados como equipamentos da AP, representa o grande diferencial do modelo de AP desde a implantação do PSF; o que decididamente impõe novos desafios à integração e planejamento regional (em que as parceiras são responsáveis por níveis de complexidade diferentes num mesmo território).

\section{Apontamentos sobre os Desafios Atuais da AP e Regionalização}

Este artigo procurou apresentar um panorama histórico geral sobre a estruturação institucional da saúde pública paulista, sob o foco dos arranjos regionais e oferta de serviços assistenciais básicos; uma questão ainda em plena efervescência.

Pouco explorada no texto, vale mencionar a questão enfrentada pelo SUS quanto às diferenças entre as realidades urbana e rural. Portanto, como releva o Pacto, não se posta "apenas" o problema da integração, mas também as especificidades regionais que incluem o desafio metropolitano. De fato, as extrapolações do ideário regionais e da AP para grandes centros têm se mostrado um desafio importante (Viana e col., 2006).
O conhecimento atual também se insurge contra o modelo clássico de administração burocrática, e cada vez mais a organização da assistência tem sido pensada em arranjos de redes; com repercussões nem sempre óbvias sobre o modo de se pensar a AP e a integração regional. A par dessa premência clínica, não se deve fugir da complexidade intersetorial e regulatória da regionalização em saúde.

Enfim, cada vez mais se explicita o problema da governança no contraditório processo de autonomia e interdependência envolvido na regionalização, no qual, sem subestimar a enorme exigência de qualificação técnica, sobressaem os desafios da costura política. Clarividência histórica que motivou o Pacto desde o início, preocupado com a reincidência da regionalização como "um conjunto de normas complexas que se sobreponham a um efetivo processo político" (Brasil, 20o6, p. 9). Não sem razão o ideário das redes integradas que se seguiu tem sua origem no campo político e traz em seu núcleo conceitos tão subjetivos quanto solidariedade, colaboração e cooperação, em franco contraste com o ideal burocrático de hierarquização e supervisão.

É justamente nesse contexto histórico que a SESSP enfrenta hoje o grande desafio de direcionar sua energia e firmar seu papel na descentralização regional do SUS, arena em que se postam uma diversidade de instâncias regionais, públicas e privadas, com e sem fins lucrativos, além da heterogeneidade de atores e interesses que atuam direta e indiretamente mediando a regulação regional da saúde.

\section{Referências}

ALVES SOBRINHO, E. J.; CAPUCCI, P. F. Saúde em São Paulo: aspectos da implantação do SUS no período de 2001-2002. Estudos Avançados, São Paulo, v. 17, n. 48, p. 209-227, maio-ago. 2003.

AYRES, J. R. O enfoque de risco na programação em saúde: fundamentos e perspectivas. Saúde e Sociedade, São Paulo, v. 4, n. 1-2, p. 72-74, jan.-dez. 1995.

BARRETO, J. B. Medicina curativa em meio rural e suas relações com os serviços de saúde pública. Archivos de Hygiene, Rio de Janeiro, v. 9, n. 1, p. 5-29, 1939. 
BARRETO, J. B. Normas para uma organização estadual de saúde pública. Archivos de Hygiene, Rio de Janeiro, v. 7, n. 2, p. 339-370, 1937.

BARBOSA, J. P. Tipos de organização sanitária aplicáveis ao Brasil. Archivos de Hygiene, Rio de Janeiro, v. 4, n. 1, p. 41-52, 1930.

BARRETO, J. B.; FONTENELLE, J. P. O systema dos centros de saúde no Rio de Janeiro. Archivos de Hygiene, Rio de Janeiro, v. 5, n. 1, p. 83-115, 1935.

BOURDIEU, P. A. Economia das trocas lingüísticas: o que falar quer dizer. São Paulo: Edusp, 2008.

BRANDÃO, G. M. Linhagens do pensamento político brasileiro. São Paulo: Hucitec, 2007.

BRASIL. Ministério da Saúde. Portaria n. 4.279, de 30 de dezembro de 201o. Estabelece diretrizes para a organização da Rede de Atenção à Saúde no âmbito do Sistema Único de Saúde (SUS). Brasília, DF: Ministério da Saúde, 2010.

BRASIL. Ministério da Saúde. Diretrizes operacionais dos Pactos pela Vida, em defesa do SUS e de gestão. Brasília, DF: Ministério da Saúde, 2006.

BRASIL. Ministério da Saúde. Portaria n. 95, de 26 de janeiro de 2001 - Norma Operacional da Assistência à Saúde NOAS-SUS 01/o2. Brasília, DF: Ministério da Saúde, 2001.

CAMPOS, A. L. Políticas internacionais de saúde na Era Vargas: o Serviço especial de saúde pública, 1942-196o. Rio de Janeiro: Fiocruz, 2006.

CAMPOS, C. E. A. As origens da rede de serviços de atenção básica no Brasil: o sistema distrital de administração sanitária. História, Ciências, Saúde-Manguinhos, Rio de Janeiro, v. 14, n. 3, p. 877-906, jul.-set. 2007.

CANDEIAS, N. M. F. Memória histórica da Faculdade de Saúde Pública da Universidade de São Paulo - 1918-1945. Revista de Saúde Pública, São Paulo, v. 18, n. Especial, p. 2-6o, dez. 1984.

CAPISTRANO FILHO, D. O programa de saúde da família em São Paulo. Estudos Avançados, São Paulo, v. 13, n. 35, p. 89-10o, jan.-abr. 1999.
FLEURY, S. M. (Org.). Projeto Montes Claros: a utopia revisitada. Rio de Janeiro: Abrasco, 1995.

FONSECA, C. Saúde no Governo Vargas (19301945): dualidade institucional de um bem público. Rio de Janeiro: Fiocruz, 2007.

GERSCHMAN, S. A democracia inconclusa: um estudo da reforma sanitária brasileira. Rio de Janeiro: Fiocruz, 1995.

GINZBURG, C. O queijo e os vermes: o cotidiano e as idéias de um moleiro perseguido pela inquisição. São Paulo: Companhia das Letras, 2002. p. 15-34.

GRANT, J. B. Health Centers and Regionalization. American Journal of Public Health, Washington, D.C., v. 43, n. 1, p. 9-13, 1953.

GUEDES, J. S. Oito anos construindo o SUS no Estado de São Paulo. Estudos Avançados, São Paulo, v. 17, n. 48, p. 229-240, maio-ago. 2003.

HABERMAS, J. Mudança estrutural da esfera pública. Rio de Janeiro: Tempo Brasileiro, 2003. (Prefácio).

HOCHMAN, G. A era do saneamento: as bases da política de saúde pública no Brasil. São Paulo: Hucitec, ANPOCS, 1998.

IBAÑEZ, N. et al. Organizações sociais de saúde: o modelo do Estado de São Paulo. Ciência \& Saúde Coletiva, São Paulo, v. 6, n. 2, p. 391-404, jul.-dez. 2001.

IBAÑEZ, N.; VIANA, A. L. Estratégias de implantação PMS. Revista do Programa Metropolitano de Saúde, São Paulo, 1986.

JASMIN, M. G. História dos conceitos e teoria política e social: referências preliminares. Revista Brasileira de Ciências Sociais, São Paulo, v. 20, n. 57, p. 27-38, fev. 2005.

JATENE, A. D. Extensão dos serviços de saúde nas áreas metropolitanas. In: CONFERÊNCIA NACIONAL DE SAÚDE, 7. Brasília. Anais... Brasília: Centro de Documentação do Ministério da Saúde, 1980. p. 49-55.

KOSELLECK, R. Uma história dos conceitos: problemas teóricos e práticos. Estudos Históricos, Rio de Janeiro, v. 5, n. 10, p. 134-46, 1992. 
LESER, W. Reorganização da Secretaria de Saúde Pública do Estado de São Paulo. In: CONGRESSO, BRASILEIRO DE HIGIENE, 17. Salvador. Anais... Salvador: Secretaria do Estado da Saúde, 1968.

LIMA, M. R. Prefácio. In: FONSECA, C. Saúde no Governo Vargas (1930-1945): dualidade institucional de um bem público. Rio de Janeiro: Fiocruz, 2007. p. 9-12.

MASCARENHAS, R. S. Contribuição para o estudo da administração sanitária estadual em São Paulo. 1949. Tese (Livre Docência) - Faculdade de Higiene e Saúde Pública da Universidade de São Paulo, São Paulo, 1949.

MASCARENHAS, R. S. "Problemas da Saúde Pública no Estado de São Paulo". Revista Paulista de Hospitais, São Paulo, n. 2 v. 2, n. 4, p 7-12, 1954.

MASCARENHAS, R. S. Serviços de saúde pública do estado de São Paulo. Arquivos da Faculdade de Higiene e Saúde Pública da Universidade de São Paulo, São Paulo, v. 18, n. 1/2, p. 51-74, 1964.

MASCARENHAS, R. S. História da saúde pública no Estado de São Paulo. Revista de Saúde Pública, São Paulo, v. 7, n. 4, p. 433-46, out.-dez. 1973.

MASCARENHAS, R. S.; PIOVESAN, A. O conceito de integração aplicado à medicina e saúde pública. Arquivos de Higiene e Saúde Pública, São Paulo, v. 26, n. 89, p. 179-98, 1961.

MASCARENHAS, R. S.; WILSON, D.; BOURROUL, G. O ensino da medicina preventiva em escolas de medicina. Arquivos da Faculdade de Higiene, São Paulo, v. 15/16, p. 17-24, 1961-1962.

MELLO, G. A.; FONTANELLA, B. J.; DEMARZO, M. P. Atenção básica e atenção primária à saúde origens e diferenças conceituais. Revista de APS, Juiz de Fora, v. 12, n. 2, p. 204-13, 2009.

NEMES, M. I. B. Ação programática em saúde: recuperação histórica de uma política de programação. In: SCHRAIBER, L. B. (Org.). Programação em saúde hoje. São Paulo: Hucitec, 1990.

PARETA, J. M.; MEIRA, A. R.; D’ANDRETTA JUNIOR, C. (Org.). Saúde da comunidade: temas de medicina preventiva e social. São Paulo: McGrawHill do Brasil, 1976.
PENIDO, H. M. A estrutura sanitária brasileira. Revista do SESP, Rio de Janeiro, v. 10, n. 1, p. 185214, 1958.

POCOCK, J. Linguagens do ideário político. São Paulo: EDUSP, 2003. p. 23-62.

PROGRAMA de saúde pública do candidato Juscelino Kubitschek. São Paulo: L. Nicollini, 1955.

RAMOS, R. A integração Sanitária: doutrina e prática. 1972. Tese (Livre-docência) - Faculdade de Saúde Pública da Universidade de São Paulo, São Paulo, 1972.

SANTOS, L. A. C.; FARIA, L. Os primeiros Centros de Saúde nos Estados Unidos e no Brasil: um estudo comparativo. Teoria e Pesquisa, São Carlos, n. 40/41, p. 137-181, 2002.

SÃO PAULO (Estado). Decreto n. 1.343, de 27 de janeiro de 1906. Divide o território do Estado em districtos sanitários e dispõe a respeito da polícia sanitária. Disponível em: <http://www.al.sp.gov.br/ legislacao/>. Acesso em: 05 maio 2011.

SÃO PAULO (Estado). Decreto n. 3.876, de 11 de julho de 1925. Reorganiza o Serviço Sanitário e repartições dependentes. Disponível em: <http:// www.al.sp.gov.br/legislacao/>. Acesso em: 05 maio 2011.

SÃO PAULO (Estado). Decreto n. 4.8o9, de 31 de dezembro de 1930. Modifica a organização do serviço sanitário do estado. Disponível em: <http://www.al.sp.gov.br/legislacao/> Acesso em: 05 maio 2011.

SÃO PAULO (Estado). Decreto n. 4.891, de 13 de fevereiro de 1931. Reorganiza o Serviço Sanitário do Estado. Disponível em: <http://www.al.sp.gov. $\mathrm{br} /$ legislacao/>. Acesso em: 05 maio 2011.

SÃO PAULO (Estado). Decreto n. 9.273, de 28 de junho de 1938. Organiza o serviço dos Centros de Saúde da Capital, do Departamento de Saúde e dá outras providências. Disponível em: <http://www. al.sp.gov.br/legislacao/>. Acesso em: 05 maio 2011.

SÃO PAULO (Estado). Decreto n. 50.192 de 13 de agosto de 1968. Dispõe sobre medidas para reforma administrativa da Secretaria de Estado dos Negócios da Saúde Pública. Disponível em: <http://www.al.sp.gov.br/legislacao/>. Acesso em: o5 maio 2011. 
SÃO PAULO (Estado). Decreto n. 22.97o, de 29 de novembro de 1984. Cria regiões de Governo e dá outras providências. Disponível em: <http://www. al.sp.gov.br/legislacao>. Acesso em: 05 maio 2011.

SÃO PAULO (Estado). Decreto n. 24.923, de 17 de março de 1986. Altera a estrutura dos Departamentos Regionais de Saúde, adequando-os às Regiões de Governo criadas pelo Decreto $n^{0} 22$. 970, de 29 de novembro de 1984. Disponível em: <http://www.al.sp.gov.br/legislacao/>. Acesso em: 05 maio 2011.

SAUVEUR, G. B. O projeto de expansão da rede de serviços básicos de saúde em São Paulo: um novo modelo ou os desdobramentos da reforma administrativa de 1969? Cadernos Fundap, São Paulo, v. 3, n. 6, p. 59-70, 1983a.

SAUVEUR, G. B. A reforma administrativa federal dos anos 60 e seus desdobramentos em São Paulo. Cadernos Fundap, São Paulo, v. 3, n. 7, p. 6o-73, $1983 b$.

SOUZA, G. P. Centro de Saúde: órgão de higiene e não assistência. Viver! Mensário de Saúde, Força e Beleza, São Paulo, n. 7, p. 13-16, jan. 1939.

SOUZA, G. P.; VIEIRA, F. B. Centro de saúde. "Eixo" de organização sanitária. Boletim do Instituto de Hygiene de São Paulo, São Paulo, n. 59, 1936.

SOUZA, J. M. et al. Curso de Saúde Pública em um semestre: algumas considerações. Revista de Saúde Pública, São Paulo, v. 9, n. 1, p. 87-92, jan.mar. 1975 .
TANAKA, O. Y. et al. Gerenciamento do setor saúde na década de 8o, no Estado de São Paulo, Brasil. Revista de Saúde Pública, São Paulo, v. 26, n. 3, p. 185-194, jun. 1992.

TELAROLLI JUNIOR, R. Poder e saúde: as epidemias e a formação dos serviços de saúde em São Paulo. São Paulo: UNESP, 1996.

VIANA, A. L. Sistema e descentralização: a política de saúde no estado de São Paulo nos anos 8o: formação e tensões. 1994. Tese (Doutorado em Economia) - Instituto de Economia da Universidade Estadual de Campinas, Campinas, 1994.

VIANA, A. L. et al. Modelos de atenção básica nos grandes municípios paulistas: efetividade, eficácia, sustentabilidade e governabilidade. Ciência \& Saúde Coletiva, Rio de Janeiro, v. 11, n. 3, p. 577-6o6, jul.-set. 2006.

VIANA, O. Populações meridionais do Brasil. Brasília: Senado Federal, Conselho Editorial, 1999.

YUNES, J. Programa Nacional de Saúde Maternoinfantil. In: CONFERÊNCIA NACIONAL DE SAÚDE, 5. Brasília. Anais... Brasília: Ministério da Saúde. 1975. p. 49-134,

YUNES, J. O SUS na lógica da descentralização. Estudos Avançados, São Paulo, v. 13, n. 35, p. 6570, jan.-abr. 1999.

YUNES, J.; BROMBERG, R. Situação da rede pública de assistência médico-sanitária na área metropolitana da Grande São Paulo. Revista de Saúde Pública, São Paulo, v. 5, n. 2, p. 221-36, dez. 1971. 